\title{
Influencia de la Corte Interamericana en el concepto de reparación integral para la consecución de la justicia en materia contencioso administrativa
}

\section{Influence of the Court on the concept of full reparation for the achievement of justice in administrative litigation}

\author{
Ileana María Boada Harker \\ Abogada, especialista en Derecho Procesal y Derecho Administrativo por la Universidad Santo Tomás Bucaramanga \\ (Col.); magister en Derecho Público por la Universidad Santo Tomás Bogotá (Col.) en convenio con la Universidad de \\ Konstanz Alemania. Docente Universidad Santo Tomás Bucaramanga (Col.). \\ Correoelectrónico:iboadah@hotmail.com
}

\begin{abstract}
Resumen
Inicia con la explicación del alcance que tiene para la Corte Interamericana el derecho al libre acceso a la administración de justicia a la luz de los artículos 8.1, 25 y 63 de la Convención Americana de Derechos Humanos, ratificada por Colombia e insertada en el ordenamiento interno a partir del bloque de constitucionalidad, para luego analizar la relación de este derecho con la reparación integral desde los casos fallados por la Corte Interamericana en los que Colombia fue condenada aun habiendo pagado indemnizaciones en la jurisdicción interna. Para concluir, se abordarán las causas que llevaron al desconocimiento por parte de la Corte Interamericana, respecto de los fallos de la jurisdicción contenciosa administrativa, como una forma de administración de justicia.
\end{abstract}

Palabras clave: Estado social de derecho, derecho al libre acceso a la administración de justicia, primacía del derecho sustancial, bloque de constitucionalidad, reparación integral.

\begin{abstract}
The text begins with the explanation of the scope it has for the Court the right to free access to the administration of justice in the light of Articles 8.1,25 and 63 of the American Convention on Human Rights, ratified by Colombia and inserted into the domestic law from constitutional block, and then analyze the relationship of this right to full compensation from the cases decided by the Court in which Colombia was convicted even having paid compensation under domestic law. In conclusion, the causes that led to ignorance of the Court, on the rulings of the administrative jurisdiction, as a form of justice will be addressed.
\end{abstract}

Keywords: Social rule of law, law on free access to the administration of justice, rule of substantive law, constitutionality block, reparation full.

\section{Résumé}

Le texte commence par l'explication de la portée qu'elle a pour la Cour, le droit à la liberté d'accès à l'administration de la justice à la lumière des articles 8.1, 25 et 63 de la Convention américaine relative aux droits de l'homme, ratifiée par la Colombie et inséré dans le le droit interne du bloc constitutionnel, puis analyser la relation de ce droit à une indemnisation intégrale des affaires tranchées par la Cour dans laquelle la Colombie a été condamné, même après avoir payé une indemnité en vertu du droit interne. En conclusion, les causes qui ont conduit à l'ignorance de la Cour, sur les décisions de la juridiction administrative, comme une forme de justice seront abordés.

Mots-clés: règle de droit social, le droit au libre accès à l'administration de la justice, la primauté du droit matériel, bloc constitutionnel, la réparation intégrale.

Recibido: 19 de mayo de 2015; Aprobado: 10 de agosto de 2015 



\section{Influencia de la Corte Interamericana en el concepto de reparación integral para la consecución de la justicia en materia contencioso administrativa*}

Ileana María Boada Harker

\section{INTRODUCCIÓN}

En el curso del proyecto de investigación denominado "El derecho al libre acceso a la administración de justicia para la realización de derechos sustanciales en materia administrativa y contencioso administrativa" se revisaron los fallos proferidos por la Corte Interamericana, en los cuales resulta condenada Colombia, pese a que existían, previa a la admisión de la demanda en esta instancia internacional, fallos internos que declaraban la responsabilidad administrativa del Estado colombiano, proferidos por la Jurisdicción Contencioso Administrativa, lo que denota como problemática el desconocimiento por parte del organismo internacional de los fallos internos como una forma de verdadera administración de justicia. Para desarrollar el tema se trabaja con los fallos internos proferidos por la Jurisdicción Contenciosa Administrativa, con los correspondientes fallos de la Corte Interamericana, y con los conceptos de acceso a la administración de justicia y reparación integral en la dimensión dada por la Corte Interamericana de Derechos Humanos.

Para determinar esta problemática se realizó el análisis desde el criterio de subsidiariedad en materia de jurisdicción y competencia de la Corte Interamericana.

* Este artículo se deriva del proyecto denominado: "El derecho al acceso a la administración de justicia para la realización de derechos sustanciales en materia administrativa y contencioso administrativa", pertenece al Grupo de Investigación Estado, Derecho y Políticas Públicas, Línea de Investigación Administración y Gobierno del Estado Social y Democrático de Derecho, Investigadora principal Ileana María Boada Harker. El proyecto pertenece a la convocatoria interna Universidad Santo Tomás Bucaramanga. 
Las citadas sentencias ${ }^{1}$ condenatorias que surgen de los casos que presenta la Comisión ante la Corte, la cual alude que pese a que en Colombia se han adelantado procesos de distinta índole, especialmente ante la jurisdicción contencioso administrativa, con el fin de esclarecer y reparar los hechos con los cuales se han vulnerado los derechos suscritos en la Convención Interamericana de Derechos Humanos ${ }^{2}$, estas formas de reparación son insuficientes ante el concepto de administración de justicia que tiene la Corte Interamericana, por lo cual se revisaron cuáles fueron las "falencias" de los fallos internos que motivaron la imposición a Colombia de nuevas sanciones de carácter internacional.

El énfasis en la jurisdicción administrativa se hace, teniendo en cuenta que en desarrollo del postulado de agotamiento de los procedimientos internos, pese a que la Corte Interamericana revisa todas las actuaciones adelantadas por las distintas autoridades del Estado demandado, en los diversos ramos de la jurisdicción (ordinaria, contenciosa administrativa, penal y especiales como la militar) y si es el caso las realizadas en materia de procedimiento administrativo (responsabilidad disciplinaria o fiscal)-, es importante el papel que debe cumplir la jurisdicción contenciosa administrativa a nivel interno, ya que es la encargada de las condenas contra "el Estado" o nación -para hacer uso de la expresión correcta-, las cuales orbitan en su competencia, a partir de la determinación de la acción u omisión de sus agentes, de las autoridades administrativas, de los particulares que desempeñan funciones administrativas, incidiendo en la responsabilidad contractual o extracontractual de la administración en sus distintos niveles (nacional o regional), razón suficiente para que sea esta jurisdicción la principal convocada a responder en sus fallos sobre las reparaciones en los términos de integralidad, tal y como lo plantea la Corte Interamericana, evitando así la procedencia de las demandas internacionales; y fijando los criterios para que el Estado administre justicia con estándares internacionales y con la plena realización de los derechos sustanciales.

La pregunta de investigación que se pretende absolver con el desarrollo de este trabajo es la siguiente: ¿De qué manera las decisiones de la Corte Interamericana de Derechos Humanos en materia de reparación integral han incidido frente a los fallos de la Jurisdicción Contencioso Administrativa, a fin de verificar si el recurso interno

1 Caso Manuel Cepeda Vargas vs Colombia, Caso Escué Zapata vs Colombia, Caso Gutiérrez Soler vs Colombia, Caso Valle Jaramillo y otros vs Colombia, Caso Masacre de Ituango vs Colombia, Caso Masacre de la Rochela vs Colombia, Caso Masacre 19 comerciantes vs Colombia, Caso Masacre de Pueblo Bello vs Colombia y Caso Las Palmeras vs Colombia.

2 También denominado Pacto de San José de Costa Rica. Colombia lo ratifica el 28 de mayo de 1973 y reconoce la competencia de la Comisión y de la Corte Interamericanas de Derechos Humanos el 21 de junio de 1985 a partir de: "Un instrumento de aceptación por el cual reconoce la competencia de la Comisión Interamericana de Derechos Humanos y de la Corte Interamericana de Derechos Humanos por tiempo indefinido bajo condición de estricta reciprocidad y para hechos posteriores a esta aceptación, sobre casos relativos a la interpretación o aplicación de la Convención, reservándose el derecho de hacer cesar la competencia en el momento que lo considere oportuno". (Recuperado de http://www.cidh.oas.org/Basicos/basicos3.htm. 
responde a los estándares internacionales de respeto y garantía al derecho de acceso a la administración de justicia?

En este escrito se defenderá la postura según la cual los fallos del juez interamericano han evidenciado las falencias del recurso interno, principalmente porque el juez contencioso administrativo no daba aplicación o no manejaba el concepto de reparación integral, el cual va más allá de la mera indemnización económica, es decir, incorpora el daño inmaterial no valorable en forma económica. La anterior situación ocasiona el irrespeto del derecho al acceso a la administración de justicia, por ello es que la Corte Interamericana se ha declarado competenete para estudiar y fallar asuntos sobre los cuales existían pronunciamientos de la Jurisdicción Contenciosa Administrativa.

Este artículo de investigación tiene un enfoque cualitativo ${ }^{3}$, cuyo método es inductivo ${ }^{4}$, partiendo del estudio de las fuentes normativas (artículos 8.1, 25 y 63 de la Convención Americana de Derechos Humanos) que tratan sobre el derecho al acceso a la administración de justicia y la reparación integral en términos internacionales, para luego pasar al análisis de los casos en los cuales ha sido condenado el Estado colombiano por la Corte Interamericana, determinando las diferencias existentes en materia contencioso administrativa que han generado este tipo de sentencias en el campo internacional. Desarrollo que se realizará desde el tipo descriptivo ${ }^{5}$ el cual es definido por Mario Tamayo como: "aquel que busca describir situaciones o acontecimientos; básicamente no está interesado en comprobar explicaciones, ni en probar determinadas hipótesis, ni en hacer predicciones" (Tamayo, 1999, p. 44)

Teniendo como muestra Colombia, se toma como población las sentencias condenatorias contra este Estado, proferidas por la Corte Interamericana de Derechos Humanos, en las que se define el concepto de reparación integral, el cual no ha sido desarrollado bajo los mismos criterios en el interior del país en lo que atañe a los procedimientos contenciosos administrativos para el resarcimiento de las víctimas por la acción u omisión de los agentes estatales.

Por otra parte, las fuentes, instrumentos y técnicas de recolección de datos para la creación de este escrito son de carácter primario, recopilados por medio de la publicación web de cada una de las sentencias.

3 Inicia inductivamente, parte de la exploración y observación cuidadosa de la realidad para recoger información, luego empieza a identificar los parámetros que la organizan y procede con esta información a diseñar la investigación, se define por la búsqueda de la comprensión que tienen los autores involucrados de la situación estudiada. Es la estrategia indicada si el objeto de estudio refiere a la realidad subjetiva.

4 El proceso de conocimiento que inicia por la observación de fenómenos particulares con el propósito de llegar a conclusiones y premisas que pueden ser aplicadas a situaciones generales de la observada (Méndez, 1999, p. 131).

5 Se pueden realizar estudios encaminados únicamente a diagnosticar la situación de un fenómeno con relación a una meta ideal sin proponer soluciones. Se hace conforme al planteamiento del problema y la operacionalización de este (Giraldo, 1999, p. 69). 


\section{EL DERECHO AL ACCESO A LA ADMINISTRACIÓN DE JUSTICIA EN COLOMBIA Y EL DESARROLLO DE ESTE POR LA CORTE INTERAMERICANA, DESDE LA CONVENCIÓN AMERICANA DE DERECHOS HUMANOS}

En la Convención Americana de Derechos Humanos en los artículos $8.1^{6}$ y $25^{7}$ bajo los títulos de "garantías judiciales" y "protección judicial" se encuentra consagrada la regulación relativa al acceso a la administración de justicia como forma de protección de los derechos reconocidos por esta, evidenciando dentro de este articulado la posibilidad que tiene todo ciudadano para poner en movimiento el aparato judicial legítimamente.

El artículo 25 se refiere al núcleo de protección del derecho al acceso a la administración de justicia desde la prontitud con que deben ser resueltos los casos, al considerar la existencia de recursos sencillos, rápidos y efectivos so pena de violar la Convención y dar paso a que por aplicación del principio de subsidiaridad opere la justicia internacional ante la mora judicial. Armonizándose este con el artículo 8.1, encaminado a la presentación de soluciones efectivas, que se dan a través de providencias, ha considerado la Corte Interamericana que el acceso a la administración de justicia:

No se agota en que se tramiten procesos internos, sino que debe además asegurar en tiempo razonable, el derecho de la víctima o sus familiares a saber la verdad de lo sucedido y a que se sancione a los eventuales responsables (Caso 19 Comerciantes vs Colombia. Párrafo 188).

Por lo que para lograr determinar en un caso si el plazo fue razonable o no, se debe tener en cuenta que la culminación de un proceso es cuando queda en firme la sentencia con el agotamiento de los recursos a que haya lugar, previéndose tres elementos para establecer el plazo razonable: "complejidad del asunto, actividad procesal del interesado y conducta de las autoridades judiciales" (Caso 19 Comerciantes vs Colombia. Párrafo 190).

6 Artículo 8.1: Garantías Judiciales: 1. Toda persona tiene derecho a ser oída, con las debidas garantías y dentro de un plazo razonable, por un juez o tribunal competente, independiente e imparcial, establecido con anterioridad por la ley, en la sustanciación de cualquier acusación penal formulada contra ella, o para la determinación de sus derechos y obligaciones de orden civil, laboral, fiscal o de cualquier otro carácter.

7 Artículo 25. Protección Judicial:

1. Toda persona tiene derecho a un recurso sencillo y rápido o a cualquier otro recurso efectivo ante los jueces o tribunales competentes, que la ampare contra actos que violen sus derechos fundamentales reconocidos por la Constitución, la ley o la presente Convención, aun cuando tal violación sea cometida por personas que actúen en ejercicio de sus funciones oficiales.

2. Los Estados Partes se comprometen: a) a garantizar que la autoridad competente prevista por el sistema legal del Estado decidirá sobre los derechos de toda persona que interponga tal recurso; b) a desarrollar las posibilidades de recurso judicial, y c) a garantizar el cumplimiento, por las autoridades competentes, de toda decisión en que se haya estimado procedente el recurso. 
No basta con la existencia formal de recursos sino que estos deben ser eficaces, es decir, deben dar resultados o respuesta a las violaciones de derechos contemplados en la Convención. No pueden considerarse efectivos aquellos recursos que, por las condiciones generales del país o incluso por las circunstancias particulares de un caso dado, resulten ilusorios (Caso 19 Comerciantes vs Colombia. Párrafo 190).

Los recursos deben responder a criterios de reparación integral ${ }^{8}$, siendo estos últimos objeto de desarrollo por la jurisprudencia de la Corte Interamericana, partiendo de que esta es una obligación del Estado, así consagrada en el artículo $63.1^{9}$ de la Convención, determinando la conminación por parte de este para que garantice que la autoridad competente prevista por el sistema legal interno tome una decisión de fondo. Esta obligación, constituye también el último núcleo de protección del acceso a la administración de justicia, pues sin fallos que resguarden los derechos conculcados, sin sentencias en términos de reparación integral, no se puede decir que se salvaguardó el derecho al acceso a la administración de justicia, muy a pesar de permitir al usuario poner en movimiento el aparato judicial y resolver su causa en forma rápida y expedita.

Estas disposiciones convencionales se insertan en el ordenamiento jurídico colombiano a través de la Ley 16 de 1972 y al incorporarlas dentro del bloque de constitucionalidad $^{10}$, dispuesto en el artículo 93 de la Constitución Política ${ }^{11}$, que determina: "Los derechos y deberes consagrados en esta Carta, se interpretarán de conformidad con los tratados internacionales sobre derechos humanos ratificados por Colombia", adquieren rango constitucional, haciéndose de imperante observancia para todo aquel que desarrolle funciones de administración de justicia, según las disposiciones generales del Título VIII, Capítulo I de la Constitución, relativas a la

8 Estos criterios se explican en el título segundo de este artículo: "La reparación integral bajo el criterio de la CIDH y el desarrollo dado en los fallos contenciosos administrativos en Colombia".

9 Artículo 63.1. [c]uando decida que hubo violación de un derecho o libertad protegidos en esta Convención, la Corte dispondrá que se garantice al lesionado en el goce de su derecho o libertad conculcados. Dispondrá asimismo, si ello fuera procedente, que se reparen las consecuencias de la medida o situación que ha configurado la vulneración de esos derechos y el pago de una justa indemnización a la parte lesionada.

10 Corte Constitucional. Sentencia C- 200 del 19 de marzo de 2002. M.P. Álvaro Tafur Galvis: "Se ha dicho que integran el bloque de constitucionalidad en sentido lato: (i) el preámbulo, (ii) el articulado de la Constitución, (iii) algunos tratados y convenios internacionales de derechos humanos (C.P. art. 93), (iv) las leyes orgánicas y, (v) las leyes estatutarias” (p. 16).

11 Artículo 93. Los tratados y convenios internacionales ratificados por el Congreso, que reconocen los derechos humanos y que prohiben su limitación en los estados de excepción, prevalecen en el orden interno. Los derechos y deberes consagrados en esta Carta, se interpretarán de conformidad con los tratados internacionales sobre derechos humanos ratificados por Colombia. El Estado colombiano puede reconocer la jurisdicción de la Corte Penal Internacional en los términos previstos en el Estatuto de Roma adoptado el 17 de julio de 1998 por la Conferencia de Plenipotenciarios de las Naciones Unidas y, consecuentemente, ratificar este tratado de conformidad con el procedimiento establecido en esta Constitución. La admisión de un tratamiento diferente en materias sustanciales por parte del Estatuto de Roma con respecto a las garantías contenidas en la Constitución tendrá efectos exclusivamente dentro del ámbito de la materia regulada en él.

* Modificado por el Acto Legislativo 1/2001. Fueron agregados incisos $3^{\circ}$ y $4^{\circ}$. 
Rama Judicial con sus arts. 228, 229 y 230, en los que se define la administración de justicia como una función pública, desconcentrada y autónoma, donde los jueces son funcionarios independientes, sometidos al imperio de la ley y en cuyas decisiones debe prevalecer el derecho sustancial sobre las formas procesales, confiriendo a toda persona la garantía constitucional de este derecho fundamental. Al respecto, la Corte Constitucional colombiana ha dicho que:

El derecho a acceder a la justicia no cumple su finalidad con la sola consagración formal de recursos y procedimientos, sino que requiere que éstos resulten realmente idóneos y eficaces. Así lo ha sostenido la Corte Interamericana de Derechos Humanos, al afirmar que: '(...) la inexistencia de un recurso efectivo contra las violaciones a los derechos reconocidos por la Convención constituye una transgresión de la misma por el Estado Parte en el cual semejante situación tenga lugar. En ese sentido debe subrayarse que, para que tal recurso exista, no basta con que esté previsto por la Constitución o la ley o con que sea formalmente admisible, sino que se requiere que sea realmente idóneo para establecer si se ha incurrido en una violación a los derechos humanos y proveer lo necesario para remediarla'. (Sentencia C- 1195 de 2001.)

Se encuentra armonía con la interpretación y alcance dados por la Corte Interamericana, generándose una integración respecto a la efectividad e idoneidad de recursos conforme a lo determinado por la instancia supranacional, debiendo generarse un criterio de unidad conceptual y material, que no da lugar a aplicación parcial o en contrario.

Para comprender todos los aspectos que a juicio de la Corte integran el derecho a la administración de justicia, podemos citar la obra de Acosta Alvarado en la que se encuentra una referencia a los aspectos que comprende o que se entienden incorporados al derecho al acceso a la justicia -"El derecho a ser oído siempre que esté en cuestión la determinación, afección o garantía de un derecho, de cualquier tipo. Por lo tanto, el derecho a contar con los mecanismos judiciales (formales o informales) idóneos y suficientes para tal efecto. -El derecho a contar con las herramientas eficaces para la solución de las controversias y la sanción de los delitos. -El derecho a un recurso efectivo para la protección de los derechos humanos. -El derecho a un tribunal independiente e imparcial. -El derecho a contar con todas las posibilidades de preparar una defensa en igualdad de condiciones. -El derecho a obtener una solución en un plazo razonable. -El derecho a una respuesta acorde con el ordenamiento jurídico, así como el derecho a que se cumpla lo previsto en ella" (Acosta y otros, 2009, pp. 20 y 21).

La comprensión de los aspectos que a juicio de la Corte componen el derecho al libre acceso a la administración de justicia, permite entender por qué a continuación la Corte además de lo ya reconocido en los fallos internos, cuantifica otro tipo de perjuicios y evidencia como insuficientes los ya declarados. 


\section{LA REPARACIÓN INTEGRAL BAJO EL CRITERIO DE LA CORTE INTERAMERICANA Y EL DESARROLLO DADO EN LOS FALLOS CONTENCIOSOS ADMINISTRATIVOS EN COLOMBIA}

Tradicionalmente en Colombia, dentro de un proceso administrativo, al declarar la responsabilidad de la administración, los perjuicios se determinan según las pretensiones de la demanda, excepcionalmente el juez toma una ruta diferente y se aparta de lo pedido por la parte para hacer declaraciones y reconocimientos que estando probados, van más allá de lo pretendido por los accionantes; en todo caso, en un sentido amplio o restringido las condenas pasan en su gran mayoría por el reconocimiento cuantitativo, bajo los criterios de: lucro cesante, daño emergente, perjuicios morales, fisiológicos, daño en la vida de relación y daño en la salud; todos estos traducibles como condenas en sumas de dinero, que para los casos llevados a la instancia internacional y que son objeto de estudio en el presente trabajo, fueron considerados por el derecho interno colombiano, en su jurisdicción contenciosa administrativa, como suficientes para cumplir con su deber de administrar justicia y reparar a las víctimas; sin embargo, a la hora de las valoraciones por parte de la Comisión Interamericana de Derechos Humanos, se termina definiendo que los mismos son insuficientes y se da vía libre al trámite de la demanda ante la Corte Interamericana.

Los casos que se presentan a continuación fueron objeto de revisión y análisis, al encontrase en estos que la jurisdicción contencioso administrativa reconoce las indemnizaciones según al criterio interno de reparación, pero que posteriormente la Corte Interamericana consideró que debía realizarse un ajuste a la condena por no haberse tenido en cuenta algunos elementos que forman parte de una reparación integral, en los términos de la Corte Interamericana de Derechos Humanos.

\section{Caso Las Palmeras vs Colombia. Sentencia del 6 de diciembre del 2001 (fondo) y Sentencia de 26 noviembre de 2002 (reparaciones y costas)}

A causa de la ocurrencia de los hechos sucedidos el 23 de enero de 1991 en la vereda Las Palmeras, departamento de Putumayo, se da inicio a dos procesos de reparación directa ante el Tribunal Contencioso Administrativo de Nariño, en los que se reconoce la responsabilidad de miembros de la fuerza pública en la vulneración de derechos contenidos en la Convención Americana de Derechos Humanos, igualmente expresa que las víctimas no pertenecían a ningún grupo armado siendo ejecutadas en estado de indefensión.

La sentencia proferida por la Corte Interamericana en su página 10, párrafo 32 expone sobre uno de los procesos, que el Tribunal Administrativo de Nariño en sentencia de primera instancia del 15 de abril de 1993 declaró responsable a Colombia por la muerte de Artemio Pantoja Ordóñez y Hernán Javier Cuarán Muchavisoy y la condenó, en consecuencia, al pago de daños y perjuicios morales y materiales 
causados a sus familiares. Se interpone el recurso de apelación y la decisión es "confirmada por la Sala de lo Contencioso Administrativo del Consejo de Estado, el 14 de diciembre de 1993” (Caso Las Palmeras vs Colombia, párr. 32).

Ordenándose como pago por concepto de daños morales y materiales más intereses corrientes y moratorios, la cantidad total de \$ 377342 481,75 millones de pesos colombianos distribuidos de la siguiente manera: 165740 863,67 millones de pesos para los familiares de Hernán Javier Cuarán Muchavisoy, y \$ 211601 618,1 millones de pesos para los familiares de Artemio Pantoja Ordóñez.

Respecto al segundo proceso, en la misma página dice:

En sentencia de primera instancia del 23 de febrero de 1995 declaró responsable a Colombia por la muerte de Julio Milciades Cerón Gómez, Edebraes Norverto Cerón Rojas y Wilian Hamilton Cerón Rojas y la condenó, en consecuencia, al pago de daños y perjuicios morales y materiales causados_a sus familiares. Esta decisión fue confirmada el 15 de enero de 1996 por la Sala de lo Contencioso Administrativo del Consejo de Estado", en segunda instancia.

Ordenándose en esta sentencia el pago por concepto de perjuicios morales y materiales la suma de \$188 288 175,45 millones de pesos colombianos, a las víctimas.

Como se observa, el Estado colombiano realizó el pago de perjuicios morales y materiales en ambos casos, incluso liquidó intereses corrientes y moratorios, sin embargo, la Comisión Interamericana de Derechos Humanos consideró que estas sumas de dinero no generaban una reparación en términos integrales a las víctimas y solicita a la Corte Interamericana que se: "ordene al Estado que otorgue una reparación a los familiares de las víctimas de acuerdo con lo estipulado en el artículo 63.1 de la Convención, mediante el pago de una indemnización justa y ordene medidas de no repetición o de satisfacción" (Sentencia de 26 noviembre de 2002 (Reparaciones y Costas), p. 28 Numeral 37). En relación con la petición de la Comisión, la Corte consideró que esta reparación del daño debe ser una restitución completa, en la que se restablezcan los derechos conculcados y en lo posible devolver las cosas al estado anterior a la vulneración, situación que en este caso no puede presentarse debido a la naturaleza de los hechos acaecidos, por tanto la Corte ha de

(...) determinar las medidas necesarias para, además de garantizar los derechos conculcados, reparar las consecuencias que las infracciones produjeron, así como establecer el pago de una indemnización como compensación por los daños ocasionados. Esta obligación de reparar que se regula, en todos sus aspectos (alcance, naturaleza, modalidades y determinación de los beneficiarios) por el derecho internacional, no puede ser modificada o incumplida por el Estado obligado, invocando para ello disposiciones de su derecho interno. Las reparaciones, como el término lo indica, consisten en las medidas que tienden a hacer desaparecer los 
efectos de las violaciones cometidas. Su naturaleza y su monto dependen del daño ocasionado en los planos tanto material como inmaterial (Sentencia de 26 noviembre de 2002 (Reparaciones y Costas), p. 29 numeral 39).

La Corte reconoce la labor del Estado colombiano de indemnizar a las víctimas, siendo estas, en el derecho interno, aquellas personas que fenecieron en la ocurrencia de los hechos, quedándole pendiente la obligación del pago de indemnizaciones a quienes reclamaron demostrando interés directo en el caso, que en derecho internacional serían estos los que están ejerciendo el rol de víctimas. Es entonces labor del Estado reparar a estas personas que resultaron igualmente afectadas, en este caso por la deficiente conducción de los procesos judiciales, especialmente en materia penal y disciplinaria, que generaron impunidad en el aparato judicial del cual el Estado es el responsable de su buen funcionamiento, además la ocurrencia de los hechos por parte de agentes del Estado que dejaron como consecuencia los daños en la honra y buen nombre de las víctimas, afectando sus relaciones laborales y sociales. Para así generar el deber de reparar los daños materiales y morales surgidos a causa de lo anteriormente indicado, y que ascendieron a la suma total de:

US\$139000 (ciento treinta y nueve mil dólares de los Estados Unidos de América) o su equivalente en moneda colombiana, correspondientes a la compensación del daño relacionado con la violación de los artículos 8.1 y 25.1 de la Convención Americana sobre Derechos Humanos. Dicha cantidad deberá ser entregada a los familiares de Julio Milciades Cerón Rojas, Wilian Hamilton Cerón Rojas, Edebraes Norverto Cerón Rojas, Hernán Javier Cuarán Muchavisoy y Artemio Pantoja Ordóñez (Sentencia de 26 noviembre de 2002 (Reparaciones y Costas), párr. 96 No. 6).

Además se decidieron otras formas de reparación dentro de las cuales se encuentran:

- El compromiso del Estado colombiano de realizar la investigación, identificación y sanción de los responsables de estos hechos en los procesos penales respectivos.

- El Estado debe publicar esta sentencia en el Diario Oficial y en un boletín de prensa de la Policía Nacional y de las Fuerzas Armadas de Colombia, por una sola vez, ya que constituye un acto de reconocimiento de responsabilidad del Estado y es por sí misma una forma de reparación y no repetición de los hechos.

\section{Caso de la Masacre de Mapiripán vs Colombia. Sentencia de 15 de septiembre de 2005}

El Ejército colombiano facilitó el transporte de paramilitares hasta Mapiripán, los cuales se tomaron el control del pueblo y procedieron a intimidar a sus habitantes, y a secuestrar y producir la muerte de otros. El 15 de julio de 1997, separaron a 27 personas identificadas en una lista, como presuntos auxiliares, colaboradores o simpatizantes de las FARC; estas personas fueron torturadas y descuartizadas 
por un miembro de las AUC conocido como "Mochacabezas". Los paramilitares permanecieron en Mapiripán hasta el 20 de julio de 1997, lapso en el cual torturaron, desmembraron, extrajeron viseras y degollaron aproximadamente a 49 personas y arrojaron sus restos al río Guaviare.

Por estos sucesos se presentaron tres demandas de reparación directa con diferentes accionantes, una es presentada en octubre de 1998, la segunda el 19 de julio de 1999 y la tercera en julio de 1999. Las dos primeras fueron acumuladas y el 1 de febrero de 2005 las partes llegaron a un acuerdo conciliatorio total por los hechos acaecidos, este fue aprobado el 1 de febrero del 2005 por el Tribunal Administrativo del Meta.

La Corte Interamericana considera que:

El aspecto sustancial de la controversia ante la Corte no es si en el ámbito interno se emitieron sentencias o se llegó a acuerdos conciliatorios por responsabilidad administrativa o civil de un órgano estatal, en relación con los violaciones cometidas en perjuicio de los familiares de algunas víctimas de los hechos de Mapiripán, sino si los procesos internos permitieron que se garantizara un verdadero acceso a la justicia conforme a los estándares previstos en la Convención Americana (Sentencia de 15 de septiembre de 2005, párr. 211).

Para dar trámite a esta situación contenciosa ante la Corte Interamericana, la Comisión Interamericana de Derechos Humanos formuló demanda, en la cual solicita se declare la responsabilidad del Estado por vulnerar las garantías consagradas en los artículos 8.1 y 25 de la Convención.

Determina la Corte respecto de la tasación del daño material, que los montos definidos en los acuerdos conciliatorios de los procesos contenciosos administrativos deberán ser deducidos de las sumas que esta fije en equidad, respecto de lo que halla probado en el curso del procedimiento internacional, estima pertinente el pago de US\$ 5000 (cinco mil dólares de los Estados Unidos de América) a favor de Luz Mery Pinzón López, Esther Pinzón López, Paola Pinzón López y María Teresa Pinzón López y de US\$ 20000 (veinte mil dólares de los Estados Unidos de América) a Mariela Contreras Cruz como daño material. Además de la suma de US\$ 985000 por concepto de daño material para 9 víctimas.

Observa luego la Corte, la indemnización por daño inmaterial realizada en los acuerdos conciliatorios en la vía contencioso administrativa, en los cuales se fijó una indemnización por concepto de daños morales a favor de los familiares de los señores Álvaro Tovar Muñoz, Sinaí Blanco Santamaría y José Rolan Valencia, versando solo frente al sufrimiento de los familiares de las víctimas, pero no respecto de estas, por lo cual considera que se debe realizar esta tasación faltante. Definiendo que para las aproximadamente 49 víctimas reconocidas por el Estado como ejecutadas o desaparecidas, ya sea individualizadas o por individualizar, la Corte fija la cantidad de US\$ 80000 (ochenta mil dólares de los Estados Unidos de América) y para los 
familiares de las víctimas montos indemnizatorios que van desde los US\$ 5000 (cinco mil dólares de los Estados Unidos de América) hasta los US\$ 50000 (cincuenta mil dólares de los Estados Unidos de América), dependiendo del grado de parentesco.

El Estado deberá desarrollar, además, las siguientes formas de reparación:

- Realizar las investigaciones pertinentes para lograr determinar y judicializar a los autores de esta masacre.

- Identificar a las víctimas desaparecidas y a sus familiares.

- Designar un mecanismo oficial que operará durante dos años, en el cual tengan participación las víctimas del presente caso.

- Prestar los servicios médicos necesarios para los familiares de las víctimas fallecidas.

- Garantizar las condiciones de seguridad para que los familiares de las víctimas, así como otros expobladores de Mapiripán, que se hayan visto desplazados, para que puedan regresar si así lo desean.

- Construir, en el plazo de un año, un monumento apropiado y digno para recordar los hechos de la masacre de Mapiripán.

- Implementar, en un plazo razonable, programas de educación en derechos humanos y Derecho Internacional Humanitario permanentes dentro de las fuerzas armadas colombianas, en todos los niveles jerárquicos.

- Publicar, dentro del plazo de seis meses, por una vez, en el Diario Oficial y en otro diario de circulación nacional, la Sección de esta Sentencia denominada "Hechos Probados", así como la parte resolutiva de la misma.

\section{Caso Masacre de Ituango y otros vs Colombia. Sentencia de 01 de julio de 2006}

En el municipio de Ituango ubicado en el departamento de Antioquia, integrado por los corregimientos de La Granja, Santa Rita y El Aro, se realizaron en el primero de ellos ejecuciones selectivas por parte de paramilitares, sin que se encontrara oposición por parte de la Fuerza Pública y a la vista de los pobladores del corregimiento. Y, posteriormente, en el Aro los paramilitares en la plaza pública humillaron y acribillaron a varios residentes, quemaron las casas, los locales y los ranchos a su alrededor. Por los hechos acaecidos en la población de El Aro se interpusieron 15 demandas, de las cuales dos no prosperaron por falta de acervo probatorio y las otras 13 fueron conciliadas con el Estado. Lo cual reconoce la Corte Interamericana, pero determina que en dichas actas de conciliación no se reconoce la responsabilidad estatal por la vulneración de diversos derechos contenidos en la Convención Americana de Derechos Humanos, ni busca la rehabilitación, resarcimiento de las víctimas, sin generar garantías de restitución y no repetición de los acontecimientos. Considerando que la reparación integral no puede reducirse al pago de compensación a los familiares de la víctima y que este debe ser tenido en cuenta por esta Corporación para fijar las reparaciones pertinentes. 
Para que la Corte Interamericana logre determinar la existencia de motivos de vulneración de los artículos 8.1 y 25 de la Convención Americana,

No depende solo si en el ámbito interno se emitieron sentencias o se llegó a acuerdos conciliatorios por responsabilidad administrativa o civil de un órgano estatal, en relación con las violaciones cometidas en perjuicio de las víctimas de violaciones a los derechos humanos o sus familiares, sino si los procesos internos permitieron que se garantizara un pleno acceso a la justicia conforme a los estándares previstos en la Convención Americana (Sentencia de 01 de julio de 2006, párr. 339).

No es solo la posibilidad de poner en marcha el aparato jurisdiccional, lo cual garantiza el derecho a acceder a la administración de justicia y la obligación de reparación, el procedimiento contencioso administrativo en sí mismo no es un recurso efectivo que por sí solo asegure la reparación integral, es un medio que obtendrá las pretensiones que le incorporen; si es usado para obtener solo reparaciones materiales, genera falencias en cuanto a la estructuración de un fallo que desarrolle medidas de rehabilitación, satisfacción, y garantías de no repetición.

La Corte Interamericana determinó que:

Los recursos como la acción de reparación directa o la acción de nulidad y restablecimiento del derecho, cuando está de por medio un acto administrativo que pueda producir daños, tiene unos alcances mínimos y unas condiciones de acceso no apropiadas para los fines de reparación que la Convención Americana establece. Como bien fue precisado por los peritos Rodrigo Uprimny y Torres Corredor, es la producción de un daño antijurídico y no la responsabilidad del Estado ante el incumplimiento de estándares y obligaciones en materia de derechos humanos lo que decreta en su sentencia una autoridad judicial en lo contencioso administrativo. En cuanto a los alcances de la sentencia, la jurisdicción contenciosa administrativa no puede más que, una vez advertido el daño, decretar la indemnización económica como fórmula única de reparación.

(...) Otros límites a un verdadero acceso a la justicia en el caso de la acción de reparación directa es que ésta es de naturaleza rogada, es decir debe ser presentada por medio de abogado, los términos ineluctables de caducidad son dos años, así como la falta de tribunales contenciosos administrativos en todas las áreas geográficas del país (Sentencia de 01de julio de 2006, párr. 341-342).

Por lo cual, en virtud del principio internacional de plena restitución la Comisión señaló que la Corte Interamericana debía fijar en equidad los montos por daños materiales e inmateriales ocurridos por vulneración de los derechos contenidos en la Convención. 
La Corte Interamericana al estudiar los acuerdos conciliatorios se da cuenta que estos contienen indemnizaciones por concepto de daños materiales y morales, los primeros deben ser tasados al monto total que en equidad considere la Corte que le corresponde a cada víctima; si el valor otorgado por el Estado, en el acta de conciliación, excede el monto determinado por la Corte Interamericana, Colombia no puede solicitar la devolución de estos dineros. Sobre los segundos considera la Corte que los acuerdos conciliatorios fijan indemnizaciones para familiares de algunas víctimas ejecutadas y por la pérdida de bienes, sin embargo, no determina un monto por los sucesos que debieron padecer las personas que fueron ejecutadas, por lo cual asigna una suma a estos, ascendiendo al valor de US\$30 000 para cada una de las 19 personas ejecutadas, además de los diversos montos aducidos en los anexos I, II y III de la sentencia.

Además se determinaron como otras formas de reparación por parte del Estado:

- La obligación de investigar y judicializar a los responsables de los hechos acontecidos.

- Prestar tratamiento gratuito, físico y sicológico a todos los familiares de las víctimas ejecutadas y entregar los medicamentos que le sean necesarios para su rehabilitación sin costo alguno.

- Generar garantías de protección y seguridad a los habitantes del municipio de Ituango.

- Presentar una disculpa pública con presencia de altas autoridades, en la que reconozca su responsabilidad internacional para los sobrevivientes de estas masacres y los familiares de las víctimas.

- Crear un programa habitacional, que les permita a quienes perdieron sus viviendas a causa de los ataques, tener una en condiciones dignas.

- Fijar una placa en un lugar público en cada uno de los corregimientos de La Granja y El Aro, para guardar la memoria de los acontecimientos.

- Capacitar a los agentes de la fuerza pública en principios y normas de protección de los derechos humanos y del derecho internacional humanitario.

- Realizar la publicación de la Sentencia, por una vez, en el Diario Oficial y en otro diario de circulación nacional.

\section{Caso de la Masacre de la Rochela vs Colombia. Sentencia de 11 de mayo de 2007}

El Estado confesó que el 18 de enero de 1989, por lo menos cuarenta miembros del grupo paramilitar "Los Masetos", contando con la cooperación y aquiescencia de agentes estatales, retuvieron a las 15 víctimas que conformaban una Comisión Judicial (Unidad Móvil de Investigación) compuesta por dos jueces de Instrucción Criminal, dos secretarios de juzgado y once miembros del Cuerpo Técnico de la Policía Judicial (CTPJ) y, posteriormente, perpetró una masacre en su contra, en la 
cual fueron ejecutados doce de ellos y sobrevivieron tres. Dicha Comisión investigaba la muerte de dos campesinos que fueron torturados y sus cuerpos regados con ácido y el caso de los 19 comerciantes.

Ante lo cual, en diversos procesos llevados a cabo en la jurisdicción contencioso administrativa se realizaron indemnizaciones o se llegaron a conciliaciones, pero nunca se declaró la responsabilidad del Estado frente a la violación de la Convención. Por una parte, se realizó un acuerdo conciliatorio entre los sobrevivientes y sus familiares con el Estado en abril de 2006, el cual fue aprobado judicialmente por el Tribunal de lo Contencioso Administrativo de Santander, el 8 de septiembre de 2006. $\mathrm{Y}$ en uno de los procesos contenciosos se dispusieron indemnizaciones por daños materiales e inmateriales a favor de 20 hermanos de 4 víctimas fallecidas (Mariela Morales Caro, Carlos Fernando Castillo Zapata, Luis Orlando Hernández Muñoz y Arnulfo Mejía Duarte).

$\mathrm{Al}$ respecto ha considerado la Corte Interamericana que estas decisiones adoptadas en el derecho interno, especialmente por la Jurisdicción de lo Contencioso Administrativa no manifiestan la responsabilidad estatal por la vulneración a la Convención, dejando de lado conceptos como los de rehabilitación, verdad, justicia, no repetición, es decir, reparación integral.

Respecto de las sumas contenidas en las indemnizaciones y acuerdos conciliatorios, considera la Corte que son suficientes para reparar adecuadamente a las víctimas y sus familiares, siendo este un avance significativo por parte del Estado colombiano respecto de la obligación de reparar.

Por otra parte, al observar la forma de calcular los montos para indemnizar los daños materiales, especialmente el lucro cesante, denota que es diferente a la utilizada por la Corte, ya que esta tiene en cuenta los ingresos que pudo obtener la víctima fallecida durante su vida probable, por lo cual la Corte Interamericana realizará una nueva liquidación por este concepto y se deberá deducir el monto ya cancelado por el Estado. Finalmente determina el pago de US\$ 2125000 (dólares americanos) en favor de las 12 víctimas fallecidas. Por otra parte, respecto del daño emergente, considera la Corte que se debe realizar un pago de US\$ 2000 (dos mil dólares de los Estados Unidos de América o su equivalente en moneda colombiana) como indemnización para cada una de las doce víctimas fallecidas. Igualmente, otorga a favor de la víctima sobreviviente Arturo Salgado Garzón la suma de US\$ 2500 (dos mil quinientos dólares de los Estados Unidos de América o su equivalente en moneda colombiana) en razón a los tratamientos médicos en los que incurrió para su recuperación.

Luego revisa el concepto de daño inmaterial y determina que los valores definidos como indemnización al respecto, por parte del Estado, se ajustaron a los diversos elementos que este tiene implícitos desde el concepto de la Corte Interamericana. Sin embargo, considera que no se dispuso una indemnización respecto del sufrimiento padecido por las víctimas fallecidas, y que es pertinente estimar montos indemnizatorios también para la víctima sobreviviente Arturo 
Salgado Garzón y de las señoras Paola Martínez Ortiz y Blanca Herrera Suárez, compañeras de dos de las víctimas fallecidas, quienes no recibieron indemnización alguna por esta clase de daño por parte del Estado. Por ello, la Corte fija, en equidad, la cantidad de US\$ 30000 (treinta mil dólares de los Estados Unidos de América o su equivalente en moneda colombiana) para cada una de las señoras Paola Martínez Ortiz y Blanca Herrera Suárez. Respecto de la víctima sobreviviente estima una cantidad de US\$ 100000 (cien mil dólares de los Estados Unidos de América o su equivalente en moneda colombiana) y por cada una de las doce víctimas fallecidas US\$ 100000 (cien mil dólares de los Estados Unidos de América o su equivalente en moneda colombiana); además determina los montos que deben recibir los familiares de las víctimas mortales, los cuales van desde US\$ 15000 (quince mil dólares de los Estados Unidos de América o su equivalente en moneda colombiana) hasta US\$ 70.000 (setenta mil dólares de los Estados Unidos de América o su equivalente en moneda colombiana) para cada uno, dependiendo su grado de parentesco (pp. 82-83).

Finalmente, en esta sentencia se disponen como otras formas de reparación por parte del Estado:

- Conducir los procesos penales que se encuentren en trámite y adoptar las medidas que permitan esclarecer los hechos.

- Garantizar a los operadores judiciales un sistema de seguridad y protección adecuada, al igual que debe implementarse un sistema de protección a testigos en casos de violación de derechos humanos.

- Brindar tratamiento médico y sicológico a los familiares de las víctimas que fallecieron, y por la víctima sobreviviente Arturo Salgado Garzón y sus familiares.

- Implementar programas permanentes de educación en derechos humanos dentro de las fuerzas armadas colombianas.

\section{Caso Valle Jaramillo y otros vs Colombia. Sentencia del 27 de noviembre de 2008}

El señor Jesús María Valle Jaramillo era un reconocido defensor de los derechos humanos en Antioquia, y para la época de los hechos se encontraba realizando las respectivas denuncias sobre la Masacre de Ituango, en la que trabajaron en forma conjunta la fuerza pública y los paramilitares; fue asesinado y la Comandancia de la IV Brigada del Ejército Nacional lo denunció penalmente y no le otorgó protección alguna. Como consecuencia de los acontecimientos se inicia acción de reparación directa ante el Tribunal Administrativo de Antioquia, y en sentencia de primera instancia no se reconoce responsabilidad alguna por parte del Estado, es recurrida la sentencia ante el Consejo de Estado, y el 26 de abril de 2007 se lleva a cabo audiencia de conciliación en la que el Estado acepta parcialmente su responsabilidad y otorga indemnización a las víctimas, por concepto de perjuicios morales, materiales debidos y materiales- indemnización futura. La cual fue aprobada el 28 de septiembre de 
2007 por la Jurisdicción Contencioso Administrativa. Por perjuicios materiales, la suma ascendió al valor de \$ 1421039 360,47 pesos colombianos, a favor de Jesús María Valle Jaramillo. Respecto de los perjuicios morales se realizó un pago de 100 SMLMV a favor de Jesús María Valle Jaramillo y 50 SMLMV a cada uno de los hermanos de la víctima. A María Nelly Valle Jaramillo se le canceló un valor adicional de aproximadamente US\$ 11000 por concepto de su propio daño inmaterial en razón de las violaciones a sus derechos.

En este caso el Estado señaló que "[p]ara el reconocimiento de [los respectivos] perjuicios se t $[\mathrm{uvo}]$ en cuenta [...] la recomendación de la Comisión Interamericana de Derechos Humanos y el acogimiento de dichas recomendaciones por el Estado [c]olombiano a través de la Resolución 001 de 2007" (Sentencia de 27 de noviembre de 2008, párr. 202), considerando la Corte Interamericana, que Colombia ha realizado un gran avance en materia de reparación, no solo por tener en cuenta las recomendaciones de la Comisión, sino también porque el Consejo de Estado desde el 2007 ha trazado desde la jurisprudencia que: "el resarcimiento económico no es suficiente, [lo cual] abre la posibilidad para que las víctimas en sus demandas [en procesos contencioso administrativos] formulen unas peticiones de reparación distintas del simple resarcimiento económico" (Sentencia de 27 de noviembre de 2008, párr. 202), con lo cual abre la posibilidad que por vía de la jurisdicción contencioso administrativa colombiana, se dé inicio a reparaciones integrales en materia de derechos humanos, según los criterios definidos por la Corte.

La Corte Interamericana evaluando las indemnizaciones que otorgó el Estado colombiano en razón a los daños materiales e inmateriales sufridos por la víctima y los familiares de esta, considera que se generó una ponderación efectiva de los derechos conculcados y que los montos respecto de los daños materiales son suficientes para el resarcimiento de los perjuicios acaecidos en el acontecimiento de los hechos, sin embargo, sobre el daño inmaterial que sufrió la señora María Nelly Valle Jaramillo, quien debió presenciar la muerte de su hermano, la Corte determina en equidad el pago adicional de US\$ 30000 por parte del Estado, y manifiesta su conformidad con el pago de los demás montos por concepto de daño inmaterial, ya que satisfacen los presupuestos de esta Corporación en términos de daño material e inmaterial.

La Comisión Interamericana de Derechos Humanos solicitó a la Corte que se tuvieran en cuenta aquellos familiares de la víctima fallecida, que no se beneficiaron del acuerdo de conciliación realizado en sede contencioso administrativa, por lo cual la Corte Interamericana se pronuncia sobre el lucro cesante y los daños inmateriales ocurridos a Carlos Fernando Jaramillo Correa, y determina en equidad el pago de US\$ 30000 por el primero y US\$ 40 000, por el último. Y un monto de US\$ 10000 que deberán ser otorgados a cada uno de los hijos y a la esposa por el daño inmaterial que sufrieron. Además de un monto de US\$ 5000 para cada una de las 13 personas que consideró la Corte no se encontraban beneficiadas por el acuerdo conciliatorio celebrado en la Jurisdicción Contenciosa Administrativa en razón al daño inmaterial. 
Igualmente se disponen como medidas adicionales de reparación que debe cumplir el Estado las siguientes:

- Realizar la investigación debida y exhaustiva con el fin de judicializar a los actores de los hechos.

- Publicar en un periódico de circulación nacional los hechos probados y la parte resolutiva de la sentencia.

- Realizar un acto público con presencia de altas autoridades del Estado para pedir perdón a las víctimas y sus familiares, resaltando la memoria de Jesús María Valle como defensor de derechos humanos.

- Elaborar una placa en memoria de Jesús María Valle Jaramillo que será fijada en el Palacio de Justicia del departamento de Antioquia, para mantener su memoria y evitar que hechos como los acaecidos vuelvan a suceder.

- Crear la Beca "Jesús María Valle Jaramillo" como apoyó a la Unidad de Defensores de Derechos Humanos de la Corte Interamericana en su trabajo por un período de dos (2) años, por una sola vez.

- Continuar con la Política de Defensores de Derechos Humanos.

- Dar asistencia médica y sicológica a las víctimas y sus familiares, en establecimientos nacionales de salud.

- Gestionar una beca para un curso y estudio en la rama, oficio y temática que las víctimas Nelly Valle Jaramillo y Carlos Fernando Jaramillo Correa, deseen estudiar. Por su afectación al proyecto de vida y vida en relación.

- Garantizar seguridad a Carlos Fernando Jaramillo para cuando decida retornar al país.

\section{Caso Manuel Cepeda Vargas vs Colombia. Sentencia de 26 de mayo de 2010}

El senador y dirigente de los partidos políticos Comunista Colombiano (PCC) y Unión Patriótica (UP), Manuel Cepeda Vargas, fue asesinado el 9 de agosto de 1994 en la ciudad de Bogotá, por su militancia política de oposición, dentro de esta situación se corroboró la participación de dos agentes de la fuerza pública. Con ocasión a ello se iniciaron dos procesos de reparación directa ante el Tribunal Contencioso Administrativo de Cundinamarca. En el primero de ellos, septiembre de 1999, se declara la responsabilidad administrativa del Estado por omisión y condena al pago de indemnizaciones para los familiares de la víctima, y en el segundo, el 8 de febrero de 2001, se condena, nuevamente, al Estado como responsable por omisión, esta sentencia es apelada por el DAS (Departamento Administrativo de Seguridad) y pasa al Consejo de Estado, el cual el 20 de noviembre del 2008 ratifica la sentencia del Tribunal, reconociéndose el pago por concepto de "lucro cesante" a favor de Olga Navia Soto de \$ 910308742 pesos colombianos. 
Pese a lo anterior y al pago de indemnizaciones, la Comisión Interamericana de Derechos Humanos solicitó a la Corte que declarara al Estado responsable por la violación de los derechos a las garantías y protecciones judiciales reconocidas en los artículos 8 y 25 de la Convención Americana, respectivamente, en perjuicio de los familiares de la víctima y que determinara las medidas de reparación, determinando en equidad el monto de las indemnizaciones por daño emergente y lucro cesante.

Los fallos [internos] no encuentran correspondencia con el verdadero alcance de la responsabilidad estatal y por tanto sustancialmente son insuficientes y parciales, así como que los criterios utilizados en dichos procesos no se ajustan a los estándares del Sistema Interamericano (Caso Manuel Cepeda Vargas vs Colombia. Sentencia de 26 de mayo de 2010).

La Corte admite la demanda y posterior a la notificación de esta el Estado reconoce su responsabilidad parcial por la vulneración de estos dos artículos convencionales, al excederse en el plazo razonable de las investigaciones por los hechos, para determinar los actores del asesinato y proceder a su judicialización en la jurisdicción penal.

Sobre las indemnizaciones canceladas por el Estado como resultado de los procedimientos contencioso administrativos incoados por los familiares de la víctima, la Corte Interamericana los estudia teniendo en cuenta la satisfacción de la no impunidad, no repetición de los actos lesivos y garantía de los derechos protegidos por la Convención,

Reparación integral de una violación a un derecho protegido por la Convención no puede ser reducida al pago de compensación a los familiares de la víctima. Una reparación integral y adecuada, en el marco de la Convención, exige medidas de rehabilitación, satisfacción y garantías de no repetición. Los resultados alcanzados en estos procesos serán tomados en cuenta al momento de fijar las reparaciones (Caso Manuel Cepeda Vargas vs Colombia. Sentencia de 26 de mayo de 2010, párr. 139).

Determinando que la jurisdicción contencioso administrativa no estableció responsabilidad institucional alguna por la comisión de los hechos por parte de agentes suyos, aun cuando al momento de las sentencias ya se tenían resultados parciales en los procesos penales y disciplinarios, que fueron evidentes en la sentencia recurrida ante el Consejo de Estado, ya que este negó la valoración de los resultados parciales de las investigaciones por haber sido remitidos en copia simple, considera la Corte Interamericana que,

Si bien no correspondía a esta vía establecer responsabilidades individuales, al determinar la responsabilidad objetiva del Estado las autoridades jurisdiccionales deben tomar en cuenta todas las fuentes de información a su disposición. Por ende, las autoridades encargadas de estos procedimientos estaban llamadas no sólo a verificar las omisiones estatales, sino a determinar los alcances reales de la responsabilidad institucional del Estado (Caso Manuel Cepeda Vargas vs Colombia. Sentencia de 26 de mayo de 2010, párr. 140). 
En consecuencia, la Corte valoró en forma positiva el pago que recibieron las víctimas y consideró que las sumas fijadas eran razonables, sin embargo, el Estado no reconoció la incursión en algunos gastos generados por los hechos violentos a algunos familiares de la víctima, por lo cual decide otorgar como daño material, en equidad, la suma de US\$ 40000 a favor de quienes debieron salir del país por concepto de tiquetes y manutención en el extranjero y US\$10 000 por otros gastos. Por otra parte, como daño inmaterial o moral, la Corte reconoce nuevamente que el Estado ya realizó el pago de 100 salarios mínimos legales mensuales vigentes (SMLMV) a favor de Iván y María Cepeda Castro, así como de Olga Navia Soto, y 500 gramos oro a cada uno de los hermanos de Manuel Cepeda Vargas y que el cálculo de estas sumas tuvieron en cuenta el dolor y las aflicciones.

Pero no tuvo en cuenta la no determinación de responsabilidad por parte de sus agentes que ya habían sido comprobados en las investigaciones internas, ordenando una compensación de US $\$ 80000$ por los daños inmateriales sufridos por el senador Manuel Cepeda Vargas. Además, estima la Corte Interamericana que en razón de la afectación sicológica y moral por la existencia de una impunidad parcial se debe cancelar una compensación adicional a la ya establecida en los procesos contencioso administrativos, siendo los montos de: US\$ 70000 a favor del señor Iván Cepeda Castro; US\$ 40000 a favor de María Cepeda Castro; US\$ 35000 a favor de Claudia Girón Ortiz; y US\$ 20000 a favor de María Estella Cepeda Vargas.

- Finalmente, como otras formas de reparación consideró que el Estado debía:

- Conducir las investigaciones internas para identificar y judicializar plenamente a los actores de los hechos punibles en la jurisdicción penal.

- Otorgar seguridad a los familiares de la víctima y prevenir su desplazamiento hacia el extranjero.

- Publicar por una sola vez, en el Diario Oficial y en otro diario de circulación nacional, algunos apartes de la sentencia y la parte resolutiva de esta. Adicionalmente, la sentencia deberá publicarse íntegramente, al menos por un año, en un sitio web oficial estatal adecuado; ya que esta por sí misma constituye una forma de reparación y un instrumento para la no repetición de esta clase de hechos.

- Realizar un acto público de reconocimiento de responsabilidad internacional por los hechos de esta sentencia.

- A crear una publicación y un documental audiovisual sobre la vida política, periodística y rol político del senador Manuel Cepeda Vargas.

- Otorgar una beca con el nombre de Manuel Cepeda Vargas.

- Brindar el tratamiento médico y psicológico que requieran las víctimas. 


\section{¿CUÁLES CONSECUENCIAS GENERA LA APLICACIÓN DEL CONCEPTO DE REPARACIÓN INTEGRAL DESARROLLADO POR LA CORTE INTERAMERICANA?}

La claridad de criterio de la Corte Interamericana, cuando en sus reiteradas intervenciones ratifica que a la hora del reconocimiento de la responsabilidad por parte del Estado, el pago de sumas en dinero a las víctimas directas o a sus familiares, no constituye criterio suficiente para poder hablar de reparación integral y, por ende, tampoco se puede predicar la satisfacción y protección efectiva del derecho al acceso a la administración de justicia.

La condena por el reconocimiento de la responsabilidad supera los límites de la indemnización material de los perjuicios; e involucra criterios como: reconocimiento público de la responsabilidad, que debe ser considerado un paso en el inequívoco camino que debe conducir a la verdad, la justicia y la reparación de las múltiples violaciones a los derechos humanos; exige que lo haga una autoridad representativa y, si es por escrito, publicarlo en un diario de amplia circulación y reconocimiento, con inserción de los hechos probados y de las condenas correspondientes. Lo antes dicho, debe cumplirse independientemente de si se trata de una causa que ha sido conciliada o es el resultado de un proceso judicial.

El compromiso real y plausible del adelantamiento correcto de las causas (penales, fiscales, disciplinarias, entre otras), que dan lugar a la identificación de los autores materiales e intelectuales, causantes de la responsabilidad administrativa; con la correspondiente verificación de que se generan las actuaciones necesarias para lograrlo; ofrecer seguridad a las víctimas sobrevivientes para evitar desplazamientos en el interior del país o fuera de él y, si este ya se produjo, crear espacios que ofrezcan condiciones de certeza frente al bienestar y la integralidad personal, permitiendo el regreso o la reubicación de los afectados; concebir mecanismos para lograr la individualización de todas las víctimas; proveer los servicios médicos (sicológicos, siquiátricos, entre otros) necesarios para su recuperación; en los casos de deshonra y difamación se exige la correspondiente rectificación, la exaltación de la verdad a través de la creación de becas, elaboración de documentos escritos o audiovisuales que demuestren y pongan en conocimiento público la historia probada que dio lugar a la condena administrativa y que, por su contenido, reivindica en su verdad a la víctima y la libera de la difamación; la construcción de monumentos que recuerden los hechos y a los caídos, para que las generaciones futuras tengan presente lo ocurrido y conozcan estos acontecimientos desafortunados que enlutan la patria, sus gentes y que por su degradación no deben repetirse; por último, y no por ello menos importante, y con el mismo objetivo del anterior, la implementación de planes de formación en protección al Derecho Internacional Humanitario, para prevenir futuras violaciones y la repetición de experiencias pasadas. Todas estas formas de reparación de perjuicios no materiales, ni traducibles en sumas de dinero pagaderas a la víctima, constituyen un criterio amplio de lo que significa, en la justicia internacional, el concepto de reparación integral. 
En cuanto al reconocimiento de sumas de dinero, además de los criterios tradicionales, forma parte de los requerimientos de la Corte, la necesidad de valorar los padecimientos de que fue objeto la víctima ejecutada. Bien puede definirse que el concepto de reparación integral de una víctima incorpora todos los elementos de reparación material, a través del pago de las sumas de dinero a que haya lugar, y que estas siempre deben ir acompañadas de condenas encaminadas a la rehabilitación, el esclarecimiento y exaltación de la verdad, la justicia y la no repetición.

La jurisdicción contencioso administrativa, a fuerza de pronunciamientos de la Corte Interamericana, ha ido incorporando dichos conceptos en su sentencias, y así lo reconoce la Corte en la sentencia del 27 de noviembre de 2008 (Caso Valle Jaramillo y otros vs Colombia), donde expresamente se felicita a Colombia por los avances; estas actuaciones de la jurisdicción, especialmente de la Sección Tercera del Consejo de Estado, han ido desmontando paulatinamente y desde hace varios años el concepto de justicia rogada, que era aplicado tan estrictamente.

Esta es una muestra clara y concreta de la incidencia de la justicia internacional sobre el desarrollo del derecho interno. Sin embargo, y pese a que estos criterios indemnizatorios y de reparación no son nuevos, se observa, en los casos anteriormente comentados, la no incorporación de fallos extra petita en la mente y cultura jurídica de los sujetos procesales que actúan ante esta jurisdicción contencioso administrativa; muchos jueces pese a que el Consejo de Estado muestra este camino y determina la existencia de este tipo de condenas, cuando sea el caso, -lo que debe darse en todos los procesos donde se encuentren probados- y teniendo en cuenta que las demandas en su gran mayoría dentro de sus pretensiones no incorporan estos pedidos; terminan haciendo reparaciones incompletas que en instancias internacionales generan una segunda condena.

Se evidencia una, la constante general debería ser que las demandas en su acápite de pretensiones y las sentencias en su parte resolutiva, siempre generen condenas que desarrollen los conceptos de justicia restaurativa, de rehabilitación, de verdad y no repetición, con lo cual se cerraría en un alto porcentaje la probabilidad de que los asuntos internos sean ventilados en instancias internacionales.

No es excusa para los abogados litigantes no invocar esta clase de reparaciones dentro de las pretensiones, esperando únicamente la posibilidad de que el juez, bajo el criterio de dirección material del proceso, pueda resolver sobre lo no pedido en relación con las condenas que comportan los criterios de reparación integral; esto no libera la responsabilidad de quienes adelantan la causa ante la jurisdicción; ya que tienen el deber de velar por los intereses y bienestar integral de sus clientes, y no solo por lo que corresponde a perjuicios tasables en sumas de dinero (que en últimas, son la base de los honorarios).

Es decir, todos los sujetos procesales deben velar y propender por la integralidad de la administración de justicia en esta rama del derecho. Es deber de todos ellos, desde la órbita constitucional, ya que es la Carta Política de 1991 la que así lo exige, al imponerles la carga de guardas de la Constitución, encargándolos de su desarrollo en 
lo que esté al alcance de cada uno en particular y en relación con las posibilidades y márgenes de su competencia.

Si se observan algunas de las exigencias de la Corte Interamericana, en relación con los criterios de reparación integral, algunos no son del resorte de la jurisdicción administrativa, y otros, por la misma forma de configuración del sistema, no le son dables a los jueces. Por ejemplo, para citar alguno de los casos: obliga a estar involucrados todos los afectados o víctimas en el fallo, porque de lo contario es posible que pueda ser procedente la demanda ante la Corte Interamericana respecto de lo excluido. Según esto, surge la pregunta: ¿qué pasa si se adelanta una causa, donde el juez echa de menos la participación en el proceso de alguna víctima que no demandó, y tampoco agotó los recursos contra los actos (si daba lugar a ello), ni intentó la conciliación prejudicial?

En estas condiciones de falta de interés procesal ¿puede o debe el juez citarla al proceso para fallar respecto de todos los afectados, como lo puede la Corte Interamericana?, o por el contrario, ¿es viable y de aceptación para esta alegar que el interés en la acción debe ser siempre una manifestación expresa de la parte, y que la falta de actividad y por ende el interés de un sujeto, debe ser motivo suficiente para ser excluido de las resultas, tanto de los procesos internos como de los internacionales?, por cuanto la característica de justicia rogada, en ese aspecto se mantiene incólume y, en materia administrativa para poner en movimiento el aparto judicial, es indispensable la petición de la parte.

En cuanto al criterio preparatorio que se refiere al compromiso real y plausible del adelantamiento correcto de las causas (penales, fiscales, disciplinarias, entre otras) que dan lugar a la identificación de los autores materiales e intelectuales, causantes de la responsabilidad administrativa, con la correspondiente verificación de que se están haciendo las actuaciones necesarias para ello, genera la siguiente reflexión: ¿Cómo puede hacerlo la jurisdicción contenciosa administrativa, sin que se presente intromisión y rompimiento del principio de independencia y autonomía que se predica entre las jurisdicciones, las instancias y los jueces? Se considera que esta clase de requerimientos es imposible que la plantee el juez administrativo de forma directa, lo máximo que él puede hacer es exponer la situación al Ministerio de Justicia, para que sea este quien se haga cargo de la vigilancia y cumplimiento de los procesos penales, civiles, fiscales y disciplinarios, originados en las mismas causas y, que dieron lugar a la declaratoria de responsabilidad administrativa.

En resumen, aunque el juez administrativo avanza y, con ello hace que se disminuya la posibilidad de que prosperen las demandas contra Colombia en la Corte Interamericana de Derechos Humanos, es fundamental enfatizar en el hecho de que los demás sujetos procesales tienen también su corresponsabilidad de velar porque sea la justicia interna la que resuelvan de forma integral los casos; porque cada vez que es admitida una demanda en la instancia internacional, es un mensaje de incumplimiento de los deberes de protección al derecho al acceso a la administración de justicia, al debido proceso y a la Convención, desmeritando el fortalecimiento y la credibilidad que requieren con urgencia las instituciones internas. 


\section{CONCLUSIONES}

En el desarrollo jurisprudencial colombiano es evidente cómo la jurisprudencia de la Corte Interamericana de Derechos Humanos ha influenciado la forma en que debe entenderse el concepto de reparación que debe ser aplicable por el Estado a la hora de ser condenado. La Sección Tercera del Consejo de Estado colombiano en los últimos años ha incluido en sus decisiones condenas que responden no solo a la reparación material de los perjuicios causados, sino que incorpora conceptos de naturaleza no material, los cuales responden a un criterio de justicia más integradora.

Los fallos hoy en día deben incluir criterios de no repetición y, en general, de reparación integral, pese a que ello no sea solicitado en los textos de la demanda, cuestión que no justifica el defecto del texto de la misma, es por esto que este artículo dentro de sus conclusiones invita a los abogados para que a la hora de elaboración de las demandas, incorporen en ellas las pretensiones que desarrollan los criterios de justicia restaurativa y reparación integral, y no dejen esto como un aspecto que debe ser supuesto y suplido por el juez.

Lograr el reconocimiento internacional de la jurisdicción interna, como una forma suficiente de administración de justicia y de protección del derecho a su acceso, es un objetivo que debe competernos a todos, y no debe ser una meta solo a cargo de la institucionalidad, los usuarios de la jurisdicción con una buena formulación de sus pretensiones contribuyen de gran forma a este propósito que es de interés general.

\section{REFERENCIAS}

Acosta, P.A. (2009). El derecho de acceso a la justicia como norma de ius cogens según la jurisprudencia interamericana. En Apuntes sobre el Sistema Interamericano (pp. 20 y 21). Bogotá: Instituto de Estudios Constitucionales Carlos Restrepo Piedrahita.

Caso 19 comerciantes vs Colombia. Sentencia de 5 de julio de 2004. Corte Interamericana de Derechos Humanos.

Caso de la masacre de Mapiripán vs Colombia. Sentencia de 15 de septiembre de 2005. Corte Interamericana de Derechos Humanos.

Caso Las Palmeras vs Colombia. Sentencia del 6 de diciembre del 2001 (Fondo). Corte Interamericana de Derechos Humanos.

Caso Las Palmeras vs Colombia. Sentencia de 26 de noviembre de 2002 (Reparaciones y Costas). Corte Interamericana de Derechos Humanos.

Caso Manuel Cepeda Vargas vs Colombia. Sentencia de 26 de mayo de 2010. Corte Interamericana de Derechos Humanos.

Caso Masacre de Ituango y otros vs Colombia. Sentencia de 01 de julio de 2006. Corte Interamericana de Derechos Humanos.

Caso Valle Jaramillo y otros vs Colombia. Sentencia de 27 de noviembre de 2008. Corte Interamericana de Derechos Humanos. 
Constitución Política de Colombia 1991, (artículos 93 y 229).

Convención Interamericana de Derechos Humanos. Pacto de San José de Costa Rica, (artículos 8, 25 y 63). Ratificado por Colombia el 28 de mayo de 1973.

Corte Constitucional. Sentencia C- 200-2002 (MP Álvaro Tafur Galvis. 19 de marzo de 2002).

Méndez, C. E. (s.f.). Metodología: guía para elaborar diseños de investigación en ciencias económicas, contables y administrativas. ( $2^{\mathrm{a}}$ ed.). Bogotá: Mc Graw Hill. 